\title{
XXXII. On the calculation of the orbits of double stars
}

\section{Professor Encke}

To cite this article: Professor Encke (1831) XXXII. On the calculation of the orbits of double stars, Philosophical Magazine Series 2, 9:51, 178-183, DOI: 10.1080/14786443108647583

To link to this article: http://dx.doi.org/10.1080/14786443108647583

曲 Published online: 01 Jun 2009.

Submit your article to this journal $\pi$

Џ Article views: 1

Q View related articles $\sqsubset$ 


\section{On the Calculation of the Orbits of Double Stars. By Professor ENCKE*.}

IT was the immortal Herschel who, among his many grand views, first directed the attention of astronomers to the highly remarkable phænomenon that so many stars are placed closely together, and to the conclusion which he drew from this circumstance, that there is great probability that two such stars, separable only by highly magnifying telescopes, are not only apparently near each other, owing to the place whence they are viewed, but that they really form in space a coordinate system; that they act upon one another, and in consequence undergo changes in their relative positions, which, after longer or shorter intervals, may be capable of observation, and whose laws may be developed in the course of time; and from that moment a new field has been opened for practical astronomy, the extent of which it is not yet possible to determine. Herschel was not satisfied with merely advancing this hypothesis, but he, in the beginning of his career, thoroughly examined the heavens, and recorded a number of observations on the relative positions of stars thus placed closely together, in order to transmit to future times safe points of comparison; and he enjoyed the satisfaction of learning, that on a new examination, after a lapse of more than twenty years, such sensible changes were observed, in several double stars, as left no doubt regarding the truth of his hypothesis. After him, Struve of Dorpat first resumed these investigations, confirmed the observations of Herschel, and after a due appreciation of his wonderful zeal, and the eminent skill evinced by him in the management of inferior means, he obtained, in the great refractor of Frauenhofer, one of the most powerful instruments for accurately investigating this subject. Herschel (the son), and South, had in the mean time likewise devoted their eminent talents to the observation of double stars; and since the new catalogue of Struve has proved the vast number of such systems; since the comparison of the observations made with different instruments, and after different methods, promises a by far greater degree of accuracy than was formerly expected; since, lastly, praçtical optics, in England, France, and Germany have, with regard to the size of instruments and the distinctness of images, reached a perfection hitherto deemed unattainable, the observations of double stars have obtained much additional interest.

Our experience is, indeed, as yet too short to derive from it any thing permanently correct; the whole space of time to

* From Encke's Ephemeris, for 1832.

which 
which it extends being hardly fifty years, during which time even the subject has neither been continually nor closely pursued, as it is at most fifteen years during which the attention of several astronomers has been simultaneously directed to it. As there are, however, a few systems of stars the observations of which embrace nearly a full revolution, and as in the case of others considerable portions of the curve in which they move may be determined, it cannot be deemed an idle speculation to apply to those distant systems the laws by which our solar system is governed, in order to perceive how far these laws may then be confirmed.

The only course we can adopt in this respect is to apply the Newtonian law. of gravity, whose truth, within the limits of our solar system, may be considered as rigorously demonstrated, and whose extension beyond those limits possesses the highest degree of probability. Agreeably to that law the relative orbits of two celestial bodies, subject only to their present mutual action on one another, will be a conic section, or, in the case here under consideration, an ellipse.

The point in which most probably such systems of stars will differ from our solar system, viz. that the difference between the two mutually attracting masses will not in them be so considerable as in the case of the sun and planets, has no influence on the orbit; and instead of considering the motions of both bodies around their common centre of gravity, we may with perfect rigour suppose the one to be at rest, as it were, in the seat of the central force. If we denote the mass, and the three coordinates, referred to an arbitrarily assumed system of three rectangular axes, of the one star by $m, x, y, z$, those of the other by $m^{\prime}, x^{\prime}, y^{\prime}, z^{\prime}$, their distance by $\rho$, and the time by $t$, the differential equations of the motion of the one star, as far as it is only acted upon by the attractive forces of the other, will be, agreeably to the Newtonian law of gravity,

$$
\begin{aligned}
& \frac{d^{2} x}{d t^{2}}+\frac{m^{\prime}\left(x-x^{\prime}\right)}{\varrho^{3}}=0, \frac{d^{2} y}{d t^{2}}+\frac{m^{\prime}\left(y-y^{\prime}\right.}{\rho^{3}}=0, \\
& \frac{d^{2} z}{d t^{2}}+\frac{m^{\prime}\left(z-z^{\prime}\right)}{\varrho^{9}}=0, \text { and those of the other star: } \\
& \frac{d^{2} x^{\prime}}{d t^{8}}+\frac{m\left(x^{\prime}-x\right)}{\varrho^{3}}=0, \quad \frac{d^{2} y^{\prime}}{d t^{2}}+\frac{m\left(y^{\prime}-y\right)}{\varrho^{8}}=0 \\
& \frac{d^{2} z^{\prime}}{d t^{2}}+\frac{m\left(z^{\prime}-z\right)}{\varrho^{3}}=0 .
\end{aligned}
$$


and from their combination we obtain the following:

$$
\begin{aligned}
& \frac{d^{2}\left(x^{\prime}-x\right)}{d t^{2}}+\frac{\left(m^{\prime}+m\right)}{\rho^{3}}\left(x^{\prime}-x\right)=0, \\
& \frac{d^{2}\left(y^{\prime}-y\right)}{d t^{2}}+\frac{\left(m^{\prime}+m\right)}{\rho^{3}}\left(y^{\prime}-y\right)=0, \\
& \frac{d^{2}\left(z^{\prime}-z\right)}{d t^{2}}+\frac{\left(m^{\prime}+m\right)}{\rho^{3}}\left(z^{\prime}-x\right)=0, \quad \text { which are the }
\end{aligned}
$$

differential equations of an elliptical motion, for which the central force $m^{t}+m$ may be supposed to reside in the one star. The knowledge of the ratio of this mass to that of the sun will not be obtained until the parallax of this pair of stars is known; nor will the ratio of $m$ and $m^{\prime}$ be ascertained until we have determined the law, according to which the centres of gravity of the different systems move about, and until by its application we can ascertain the position of that point between the two stars, for which it is true, or of their common centre of gravity*. Our observations do not refer to the ellipse actually described by the moving star about the one at rest, but to its projection on a plane vertical to the line of vision. The projection of a conic section on a plane any how inclined being likewise a conic section, the projection will in our case likewise be an ellipse, with this difference only, that the star at rest will no longer be in its focus. The determination of the orbit of the double stars is, therefore, on the one hand incomparably more easy than the determination of the orbits of planets, inasmuch as the change of position of the observer does not come into consideration. But, on the other hand, it is more difficult, because the focus itself of the ellipse is not given, but only its projection in the projected ellipse, and the mass being unknown, the measure of areal velocity is wanting. As, therefore, in the case of planets, six data or elements are sufficient, because by them, combined with the known mass of the sun, or the $k$ in Gauss's Theoria Motuis, \&c. which depends on it, the areal velocity itself is given, so in the case of double stars this latter must be separately ascertained, and we want, consequently, the determination of seven elements.

Every observation gives, besides the moment of time, two coordinates in the plane of the projected ellipse, which determine the relative position of the moveable stars with regard to the one at rest. Three complete observations or the six quantities obtained by them, and independent of one another,

* See Bessel, in Zach's Monthly Corresp. 1812, August, p. 161. 
are not sufficient for the determination of seven elements. Four observations are still more than sufficient. In a similar manner however, to the determination of the orbit of a comet, the superfluous datum of the four observations may be made use of for obtaining, in conjunction with another, a datum which is more suitable to the calculation, or it may be employed for any other particular purpose, and for facilitating the develop-. ment. If the time were not to be taken into consideration at all, it would be necessary; the ellipse having five constants in its most general equation, to have five distances, with their intermediate angles, in order to obtain the projected ellipse. The condition that the point from which the distances have been taken, is the projection of the focus of the true ellipse, would give the position of the plane, and consequently its true form. If, however, the observations were in other respects incomplete; if, for instance, at a given time only one of the polar coordinates, perhaps only the angle of position, as it is called, had been observed, and as it will be by no means advisable to neglect an element, which is so easily obtained as the time, we should require as many observations as there are elements to be determined; viz. seven.

The latter case may perhaps arise in future, as, according to our present experience, it is more easy to determine the angle of position with a certain degree of accuracy, than the distance. For the present time, however, it would be superfluous to found the determination of an orbit on such incomplete observations, which presents, as it appears, greater difficulties than that founded on the emplayment of complete observations. The epochs are as yet not distant enough from one another to allow the selection of seven of them. I limit my investigations, therefore, to the case of four complete observations, from which the orbit of a double star is to be derived.

M. Savary has already treated the same subject in the Conn. des Temps for 1830, and has illustrated his methods by an application to $\xi$ Urs. Maj. in such a manner as to present in his calculations a closer conformity to the observations, than could have been expected from the difficulty of obtaining them. The difference of his deduction from that which here follows, consists perhaps only in his employing the properties of the ellipse when referred to its conjugate diameter; while my investigations are founded on the relations usually employed in astronomy. My formulæ may also, perhaps, be more convenient for calculation.

Let the star which is considered to be at rest be the point of beginning of the coordinates, and let the times of the observations in their proper order be $t_{1}, t_{2}, t_{3}, t_{4}$.

The 
182 Prof. Encke on the Calculation of the Orbits of Double Stars.

The observations commonly give immediately the polar coordinates of the moveable star, when the angles are reckoned, sometimes from the circle of declination, sometimes from the parallel of the star at rest. Let the angles reckoned from any one of the principal axes, in the direction of the motion, from $0^{\circ}$ to $360^{\circ}$, be designated by $p_{1}, p_{2}, p_{3}, p_{4}$; and let the distances be expressed by $\rho_{1}, \rho_{2}, \rho_{3}, \rho_{4}$. In comparing linear dimensions it is more convenient to have rectangular coordinates. If we consider, therefore, the principal axis as the axis of one of the coordinates, and an axis perpendicular to. it as that of the others, we have, with due regard to the signs of the trigonometrical functions,

$$
\begin{aligned}
& \xi_{1}=p_{1} \cos p_{1}, \xi_{2}=p_{2} \cos p_{2}, \xi_{3}=p_{3} \cos p_{3}, \xi_{4}=p_{4} \cos p_{4} \\
& \eta_{1}=p_{1} \sin p_{1}, \eta_{2}=p_{2} \sin p_{2}, \eta_{3}=p_{3} \sin p_{3}, \eta_{4}=p_{4} \sin p_{4}
\end{aligned}
$$

If we designate the origin of the coordinates by 0 , and the respective places of the star by $1,2,3,4$, and the double areas of the triangles inclosed by any three of these five points, by the respective three numbers in parentheses, we have the following six expressions:

$$
\begin{aligned}
& \left(\begin{array}{lll}
0 & 1 & 2
\end{array}\right)=\rho_{1} \rho_{2} \sin \left(p_{2}-p_{1}\right)=\eta_{2} \xi_{1}-\eta_{1} \xi_{2} \\
& \left(\begin{array}{lll}
0 & 1 & 3
\end{array}\right)=\rho_{1} \rho_{3} \sin \left(p_{3}-p_{1}\right)=\eta_{3} \xi_{1}-\eta_{1} \xi_{3} \\
& \left(\begin{array}{lll}
0 & 1 & 4
\end{array}\right)=\rho_{1} \rho_{4} \sin \left(p_{4}-p_{1}\right)=\eta_{4} \xi_{1}-\eta_{1} \xi_{4} \\
& \left(\begin{array}{lll}
0 & 2 & 3
\end{array}\right)=\rho_{2} \rho_{3} \sin \left(p_{3}-p_{2}\right)=\eta_{3} \xi_{2}-\eta_{2} \xi_{3} \\
& \left(\begin{array}{lll}
0 & 2 & 4
\end{array}\right)=\rho_{2} \rho_{4} \sin \left(p_{4}-p_{2}\right)=\eta_{4} \xi_{2}-\eta_{2} \xi_{4} \\
& \left(\begin{array}{lll}
0 & 3 & 4
\end{array}\right)=\rho_{3} \rho_{4} \sin \left(p_{4}-p_{3}\right)=\eta_{4} \xi_{3}-\eta_{3} \xi_{4}
\end{aligned}
$$

From their combination the triangles between the places themselves may be derived. We have

$$
\begin{aligned}
& \left(\begin{array}{lll}
1 & 2 & 3
\end{array}\right)=\left(\begin{array}{lll}
0 & 1 & 2
\end{array}\right)+\left(\begin{array}{lll}
0 & 2 & 3
\end{array}\right)-\left(\begin{array}{lll}
0 & 1 & 3
\end{array}\right) \\
& \left(\begin{array}{ll}
1 & 2
\end{array}\right)=\left(\begin{array}{lll}
0 & 1 & 2
\end{array}\right)+\left(\begin{array}{lll}
0 & 2 & 4
\end{array}\right)-\left(\begin{array}{lll}
0 & 1 & 4
\end{array}\right) \\
& \left(\begin{array}{lll}
1 & 3 & 4
\end{array}\right)=\left(\begin{array}{lll}
0 & 1 & 3
\end{array}\right)+\left(\begin{array}{lll}
0 & 3 & 4
\end{array}\right)-\left(\begin{array}{lll}
0 & 1 & 4
\end{array}\right) \\
& \left(\begin{array}{ll}
2 & 34
\end{array}\right)=\left(\begin{array}{ll}
023 \\
0
\end{array}\right)+\left(\begin{array}{lll}
0 & 34
\end{array}\right)-\left(\begin{array}{ll}
0 & 24
\end{array}\right)
\end{aligned}
$$

which, however, are connected together by the following equation of condition:

$$
\text { (C) }\left(\begin{array}{llll}
1 & 2 & 3 & 4
\end{array}\right)=\left(\begin{array}{lll}
1 & 2 & 3
\end{array}\right)+\left(\begin{array}{lll}
1 & 3 & 4
\end{array}\right)=\left(\begin{array}{lll}
1 & 2 & 4
\end{array}\right)+\left(\begin{array}{lll}
2 & 3 & 4
\end{array}\right) \text {. }
$$

Agreeably to the nature of the ellipse, the signs of the areas (B) must always be positive. A negative sign in the areas (A) denotes that if the triangle be conceived to be formed by the movement of the distance to which the greater index belongs, a movement through an angle of more than $180^{\circ}$ in the positive direction has taken place.

If we denote, in a similar manner, the chords between 
any two of the four places by the respective two numbers in parentheses, we have

$$
\begin{aligned}
& \left(\begin{array}{ll}
1 & 2
\end{array}\right)^{2}=\left(\xi_{2}-\xi_{1}\right)^{2}+\left(\eta_{2}-\eta_{1}\right)^{2} \\
& \left(\begin{array}{ll}
1 & 3
\end{array}\right)^{2}=\left(\xi_{3}-\xi_{1}\right)^{2}+\left(\eta_{3}-\eta_{1}\right)^{2} \\
& \left(\begin{array}{ll}
1 & 4
\end{array}\right)^{2}=\left(\xi_{4}-\xi_{1}\right)^{2}+\left(\eta_{4}-\eta_{1}\right)^{2} \\
& \left(\begin{array}{ll}
2 & 3
\end{array}\right)^{2}=\left(\xi_{3}-\xi_{2}\right)^{2}+\left(\eta_{3}-\eta_{2}\right)^{2} \\
& \left(\begin{array}{ll}
2 & 4
\end{array}\right)^{2}=\left(\xi_{4}-\xi_{2}\right)^{2}+\left(\eta_{4}-\eta_{2}\right)^{2} \\
& \left(\begin{array}{ll}
3 & 4
\end{array}\right)^{2}=\left(\xi_{4}-\xi_{3}\right)^{2}+\left(\eta_{4}-\eta_{3}\right)^{2}
\end{aligned}
$$

The equations (A) (B) (C) (D) contain the data of the observations.

[To be continued.]

XXXIII. A Botanical Description of Hermione Cypri. By A. H. H AworTH, F.L.S. \&;c. \&c.

To the Editors of the Philosophical Magazine and Annals. Gentlemen,

IN my last communication to your useful Magazine, N. S. vol. viii. p. 130, it was stated, under the description of Hermione tenuifiora, that the double and semi-double flowering varieties, hitherto proposed doubtingly under it, were probably of another and distinct species, supposed to come from the Island of Cyprus, which I there designated H. Cypri.

At that time the flowers, in their single state, had not fallen under my examination. In fact I never could procure or find the plant in that state until the present time; when the acute eye of my friend $\mathrm{Mr}$. Sweet detected a specimen of it, nearly in full bloom, amongst Mr. Colvill's forced bulbs, at his noble Nursery in the King's Road; whither I went to examine it, and there saw along with other bulbous plants, in full bloom, the most showy and best managed collection of Hybrid Amaryllid I ever beheld.

I had no sooner pronounced the Hermione Cypri new to me, and to be undescribed, by any modern writer at least, in its single state, than Mr. Colvill, with his usual kindness towards belping me to elucidate this beautiful tribe of plants, made me a present of it; although it was the only one in his extensive collection.

I am the more flattered at this, because it enables me to show that the conjecture I made, as above cited, concerning the distinctness of this species, has not proved incorrect. And I hope to persuade $\mathrm{Mr}$. Sweet to give the botanical world a representation of it, from the pencil of his excellent artist Mr. Smith, in an early Number of his beautiful British Flower

Garden. 